\title{
Laparoscopic Versus Open D2 Gastrectomy for the Treatment of Gastric Cancer: a Singapore Institution's Experience over 7 Years
}

\author{
Danson Yeo MBBS, FRCSEd ${ }^{1}$, Enming Yong MBBS, FRCSEd ${ }^{2 *}$, Charleen Yeo MBBS, \\ MRCSEd $^{3}$, Jaideepraj Rao MBBS, FRCS ${ }^{4}$, Aaryan Koura MBBS ${ }^{4}$, Sanghvi Kaushal MBBS, \\ FRCSEd $^{5}$, Aung Myint Oo MBBS, FRCSEd ${ }^{5}$ \\ ${ }^{1}$ Associate Consultant, Upper Gastrointestinal Surgery Unit, Department of General Surgery, Tan Tock Seng \\ Hospital, 11 Jalan Tan Tock Seng, Singapore 308433 \\ ${ }^{2}$ Associate Consultant, Department of General Surgery, Tan Tock Seng Hospital, 11 Jalan Tan Tock Seng, \\ Singapore 308433 \\ ${ }^{3}$ Resident, Upper Gastrointestinal Surgery Unit, Department of General Surgery, Tan Tock Seng Hospital, 11 \\ Jalan Tan Tock Seng, Singapore 308433 \\ ${ }^{4}$ Senior Consultant, Upper Gastrointestinal Surgery Unit, Department of General Surgery, Tan Tock Seng \\ Hospital, 11 Jalan Tan Tock Seng, Singapore 308433 \\ ${ }^{5}$ Consultant, Upper Gastrointestinal Surgery Unit, Department of General Surgery, Tan Tock Seng Hospital, 11 \\ Jalan Tan Tock Seng, Singapore 308433 \\ *Corresponding Author: Dr. Aung Myint Oo, Consultant, Upper Gastrointestinal Surgery Unit, Department \\ of General Surgery, Tan Tock Seng Hospital, 11 Jalan Tan Tock Seng, Singapore, E-mail: Myint_Oo_Aung@ \\ ttsh.com.sg
}

\begin{abstract}
Introduction: Gastric cancer is a leading cause of cancer related mortality in Singapore and open surgical resection with en-bloc lymphadenectomy is currently the standard of care. While the benefits of laparoscopic surgery for other cancers such as colorectal cancer have been widely accepted. It has seen slower acceptance for gastric cancer due to the steep learning curve, concerns regarding long-term oncological outcome and adequacy of harvested lymph nodes. Our study aims to compare our institution's short term outcomes of laparoscopic gastrectomies ( $L G)$ for cancer to open gastrectomy $(O G)$.
\end{abstract}

Materials \& Methods: A retrospective review of patients who underwent gastrectomies for stomach cancer from July 2008 to December 2015 was done. All patients underwent either partial or total gastrectomy with the intention of D2 lymphadenectomy as per the Japanese gastric cancer guidelines by one of four upper gastrointestinal consultant surgeons. The decision to undertake an open or laparoscopic approach was made after discussion between the surgeon and the patient. Patients who had metastatic gastric cancer or underwent gastrectomy for palliation were excluded. All patients were followed up for at least five years postoperatively. Patient demographics, tumour characteristics, operative details, and post-operative outcomes were analysed using SPSS version 21.

Results: 164 patients underwent gastrectomies between 2008 and 2015. 58 were OG and 106 were LG. There were 9 conversions from laparoscopic to open surgery. More stage III cancers underwent $O G(n=43)$ while stage I and II cancers underwent LG $(n=75)$. The laparoscopic group had longer operative time (268 min vs $223 \mathrm{~min}, \mathrm{p}<0.001)$ with a non-significant trend towards less blood loss (287ml vs 330ml) and shorter length of stay (10 days vs 13 days). There was no significant difference between number of lymph nodes harvested (35 vs 32), re-operation rate, 30-day morbidity and mortality. There was a significantly higher recurrence rate $(43 \%$ vs $15 \%, P<0.001)$ with $O G$, however this did not affect overall survival between $O G$ and LG $(25$ months vs 30 months, $P=0.173$ ).

Conclusion: The number of lymph nodes harvested and 30-day morbidity of LG is equivalent to the current gold standard of $O G$. The higher recurrence rate of open surgery is likely due to more OG being performed for higher stage tumours. Our study shows that LG for gastric cancer is safe and feasible in experienced hands. 


\section{INTRODUCTION}

Gastric cancer is the seventh most common cancer among males in Singapore, and the third leading cause of cancer death worldwide.(1) Despite advances in chemotherapy, radiotherapy and targeted therapy, surgery remains the only method to achieve cure for gastric cancer.(2) Open surgical resection with en-bloc lymphadenectomy is currently the standard of care for gastric cancer.

The first laparoscopic-assisted distal gastrectomy with modified D1 lymph node dissection was performed in 1994 by Kitano(3) for the treatment of early gastric cancer. While the use of laparoscopic surgery for early gastric cancer is largely accepted, the use of laparoscopic gastrectomy for advanced gastric cancer is still controversial.(4) Laparoscopic gastrectomy has short term advantage in the early recovery of patients such as decreased intra-operative blood loss and post-operative early morbidity.(5)

While laparoscopic surgery for surgical procedures like appendectomies and cholecystectomies is starting to replace open surgeries, laparoscopic gastrectomy has seen slower acceptance for gastric cancer. Cited limitations include its steep surgical learning curve, initial concerns regarding long-term oncological outcome and adequacy of harvested lymph nodes.

Laparoscopic gastrectomies have been performed in our institution since 2008. The purpose of this study is to evaluate the shortterm outcomes of laparoscopic gastrectomies for gastric cancer compared to open gastrectomy in our institution.

\section{METHODS}

This retrospective review was performed with the approval of the Institution Review Board (Reference number; 2016/01052). The study cohort included patients who underwent either open or laparoscopic gastrectomies for histologically confirmed gastric adenocarcinoma from January 2008 to December 2015. Patients who had Stage 4 gastric cancer, underwent gastrectomy for palliation, or underwent gastrectomy for recurrent gastric cancer were excluded from this study. The decision to undertake either an open or laparoscopic approach was made after discussion between the attending surgeon and the patient. The surgery was performed by one of four upper gastrointestinal consultant surgeons in our institution. All partial or total gastrectomies were performed with the intention of a D2 lymphadenectomy as per Japanese gastric cancer treatment guidelines. Morbidity was graded according to the Clavien Dindo classification and included for analysis if they were Grade 2 and above.

\subsection{Patient Characteristics and Clinical Data}

Patient characteristics were obtained from a review of the medical records. Demographic data included age at diagnosis, sex, race, American Society of Anesthesiologists (ASA) physical status classification score and body mass index. Clinicopathological characteristics included the location of the tumours, histological grade, TNM stage and operation method. Stage at diagnosis was determined according to the 7th Edition of TNM staging system of gastric cancer, in accordance with the American Joint Committee on Cancer (AJCC) classification system. Operative outcomes such as 30-day morbidity and mortality, as well as recurrence and survival were included.

\subsection{Follow-Up Schedule}

All patients were followed up for five years, three monthly for the first two years, and six monthly for the subsequent three years. Annual Computer Tomographic (CT) scans of the abdomen and pelvis, and gastroscopy were performed to assess for local and distant recurrence. Those losses to follow-up and deaths were treated as censored.

\subsection{Statistical Analysis}

Patient demographics, tumour characteristics, operative details and post- operative outcomes were analyzed using SPSS version 21 for windows (SPSS Inc., Chicago, Il, USA). Data was presented as mean and standard deviations for variables that following normal distribution and were analyzed by $\mathrm{t}$ test. For variables following non-normal distribution, results were expressed as median and range, and were compared with nonparametric tests. Semiquantitative results were analyzed by MannWhitney U-test, while categorical results were analyzed by chi-square tests or Fisher exact test as appropriate. The overall survival was assessed from the date of gastrectomy until the last follow up or death or any cause. The disease-free survival was calculated from the date of gastrectomy until the date of cancer recurrence or death from any cause. Recurrence and disease free- survival curves were generated by Kaplan-Meier method, and analyzed using 
Laparoscopic Versus Open D2 Gastrectomy for the Treatment of Gastric Cancer: a Singapore Institution's Experience over 7 Years

the log rank test. Statistical significance was taken at the level of $\mathrm{P}$ value less than 0.05 . The analysis was performed on an intention-to-treat basis.

\section{RESULTS}

\subsection{Patient Demographics}

There were a total of 164 patients who underwent gastrectomies for gastric cancer from 2008 to 2015 in our institution. Mean age was 67 years old, $63 \%(n=104)$ of them were of male

Table1. Patient demographics \& disease characteristic

\begin{tabular}{|c|c|c|c|c|c|}
\hline & & All $(\mathrm{N}=164)$ & Open & Laparoscopy & \\
\hline & & $\mathbf{N}(\%)$ & $n=58$ & $n=106$ & P value \\
\hline Age at diagnosis & mean \pm SD & $67 \pm 11.1$ & $67.6 \pm 11.2$ & $66.6 \pm 11.1$ & 0.584 \\
\hline \multirow[t]{2}{*}{ Gender } & Female & $60(36.6)$ & $19(32.8)$ & $41(38.7)$ & 0.452 \\
\hline & Male & $104(63.4)$ & $39(67.2)$ & $65(61.3)$ & \\
\hline \multirow[t]{4}{*}{ Race } & Chinese & 153(93.4) & $55(94.8)$ & $98(92.5)$ & 0.704 \\
\hline & Malay & $3(1.8)$ & 0 & $3(2.8)$ & \\
\hline & Indian & $4(2.4)$ & $1(1.7)$ & $3(2.8)$ & \\
\hline & Others & $4(2.4)$ & $2(3.5)$ & $2(1.9)$ & \\
\hline Body mass index (BMI) & mean \pm SD & $22.9 \pm 3.9$ & $21.8 \pm 3.5$ & $23.4 \pm 4$ & 0.012 \\
\hline \multirow[t]{2}{*}{ Previous laparotomy } & No & 151(92.1) & $48(82.8)$ & 103(97.2) & 0.002 \\
\hline & Yes & $13(7.9)$ & $10(17.2)$ & $3(2.8)$ & \\
\hline \multirow[t]{4}{*}{$\begin{array}{l}\text { American Society of Anaesthesiologist } \\
\text { (ASA) score }\end{array}$} & 1 & $9(5.5)$ & $2(3.5)$ & $7(6.6)$ & 0.095 \\
\hline & 2 & $90(54.9)$ & $26(44.8)$ & $64(60.4)$ & \\
\hline & 3 & $63(38.4)$ & $29(50)$ & $34(32.1)$ & \\
\hline & 4 & $2(1.2)$ & $1(1.7)$ & $1(0.9)$ & \\
\hline \multirow[t]{4}{*}{ Location of tumour } & Upper & $39(24.1)$ & $21(36.8)$ & $18(17.1)$ & 0.004 \\
\hline & Mid & $31(19.1)$ & $14(24.6)$ & $17(16.2)$ & \\
\hline & Lower & $86(53.1)$ & $20(35.1)$ & $66(62.9)$ & \\
\hline & Diffuse & $6(3.7)$ & $2(3.5)$ & $4(3.8)$ & \\
\hline \multirow[t]{5}{*}{ Histological grade } & Well & $3(2)$ & $3(5.3)$ & 0 & 0.254 \\
\hline & Mod & $58(38.9)$ & $20(35.1)$ & $38(41.3)$ & \\
\hline & Poor & $78(52.4)$ & $30(52.6)$ & $48(52.2)$ & \\
\hline & Undifferentiated & $6(4)$ & $2(3.5)$ & $4(4.4)$ & \\
\hline & Others & $4(2.7)$ & $2(3.5)$ & $2(2.2)$ & \\
\hline \multirow[t]{4}{*}{ T stage } & $\mathrm{T} 1$ & $59(36.2)$ & $8(14)$ & $48(45.3)$ & $<0.001$ \\
\hline & $\mathrm{T} 2$ & $22(13.5)$ & $3(5.3)$ & 19(17.9) & \\
\hline & T3 & $51(31.3)$ & $27(47.4)$ & $24(22.6)$ & \\
\hline & $\mathrm{T} 4$ & $31(19)$ & $18(31.6)$ & $13(12.3)$ & \\
\hline \multirow[t]{5}{*}{$\mathrm{N}$ stage } & 0 & $63(39.1)$ & $10(18.2)$ & $53(50)$ & $<0.001$ \\
\hline & N1 & $27(16.8)$ & $10(18.2)$ & $17(16)$ & \\
\hline & $\mathrm{N} 2$ & $26(16.2)$ & $10(18.2)$ & $16(15.1)$ & \\
\hline & N3 & $25(15.5)$ & $11(20)$ & $14(13.2)$ & \\
\hline & N4 & $20(12.4)$ & $14(25.4)$ & $6(5.7)$ & \\
\hline \multirow[t]{3}{*}{ Overall stage } & I (IA, IB) & $55(34.5)$ & $5(8.9)$ & $49(46.2)$ & $<0.001$ \\
\hline & II (IIA, IIB) & $32(19.8)$ & $6(10.7)$ & $26(24.5)$ & \\
\hline & III (IIIA, IIIB) & 74(45.7) & $43(76.8)$ & $31(29.3)$ & \\
\hline \multirow[t]{2}{*}{ Neoadjuvant chemo } & No & $154(94.5)$ & $51(89.5)$ & $103(97.2)$ & 0.067 \\
\hline & Yes & $9(5.5)$ & $6(10.5)$ & $3(2.8)$ & \\
\hline \multirow[t]{2}{*}{ Adjuvant chemo } & No & $82(50.3)$ & $22(38.6)$ & 60(56.6) & 0.028 \\
\hline & Yes & $81(49.7)$ & $35(61.4)$ & $46(43.4)$ & \\
\hline
\end{tabular}

\subsection{Disease Characteristics}

Table 1 demonstrates the disease characteristics of our patient population. Majority of the gastric cancers were in the distal stomach $(n=86,53 \%)$, gender, and majority were Chinese $(\mathrm{n}=153$, 93\%). Average body mass index (BMI) was $22.9 \mathrm{~kg} / \mathrm{m}^{2}$, and majority had an American Society of Anaesthesiologists (ASA) score of either $2(n=90,55 \%)$ or $3(n=63,38 \%)$. Patients who underwent laparoscopic resection had a significantly higher BMI as compared to those who went for open surgery (23.4 vs $21.8 \mathrm{~kg} / \mathrm{m}^{2}$, $\mathrm{p}=0.012$ ). Patient demographic details are further elaborated in Table 1. remaining were either mid-gastric cancers or diffuse cancers. There were $55(35 \%), 32$ $(20 \%)$, and 74 (46\%) Stage 1, 2, and 3 gastric 
cancers respectively. Laparoscopic resection $(n=49)$ was performed more for patients with early Stage 1 gastric cancers as compared to open resection $(n=5)$. Accordingly, open surgery $(n=43)$ was favoured in advanced gastric cancers (Stage 3) as compared to laparoscopic $(n=31)$. In terms of histological grade, majority of them were either moderately $(\mathrm{n}=58,39 \%)$ or poorly $(\mathrm{n}=78,52 \%)$ differentiated cancers. 9 $(6 \%)$ patients and $81(50 \%)$ patients underwent neoadjuvant and adjuvant chemotherapy respectively.

\subsection{Outcomes}

There were 9 conversions from laparoscopic to open surgery. The mean operative time for laparoscopic surgery was significantly longer than that of open surgery (268 mins vs 223 mins, $\mathrm{p}=0.001)$. The laparoscopic group also had lesser intra-operative blood loss as compared to the open group (287 vs 330 millilitres), although this was not statistically significant $(p=0.444)$. The length of stay was

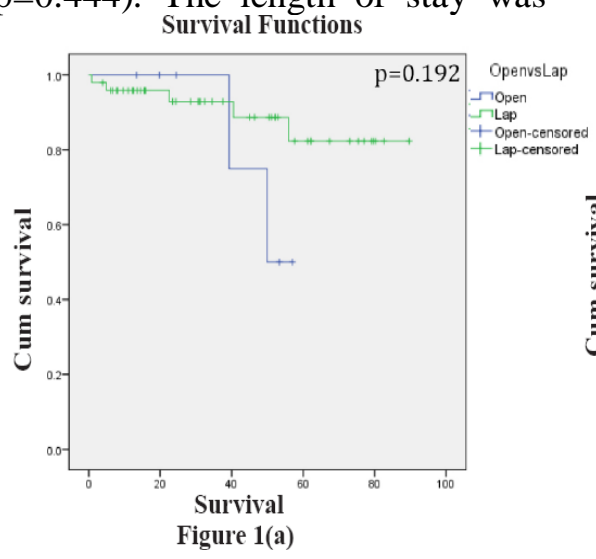

also shorter in the laparoscopic compared to open group (10 vs 13 days), however this was also not statistically significant $(\mathrm{p}=0.131)$. When comparing laparoscopic versus open surgery, there was no significant difference between number of lymph nodes harvested (35 vs 32), and re-operation rate (5\% vs $3 \%$ ). Patients who underwent open gastrectomy had a high rate of recurrence ( $44 \%$ vs $15 \%, \mathrm{p}<0.001)$ and overall mortality ( $47 \%$ vs $26 \%, \mathrm{p}=0.007)$ as compared to the laparoscopic group. The difference in survival between open and laparoscopic surgery is likely related to the more advanced disease profile of the open surgery group. Kaplan Meier survival curves for survival and time to recurrence by stage of disease showed no statistical difference between both surgery techniques (Fig. 1-3). There was no statistically significant difference between 30-day morbidity and 30-mortality between both groups, as further demonstrated in Tables 2 and 3.

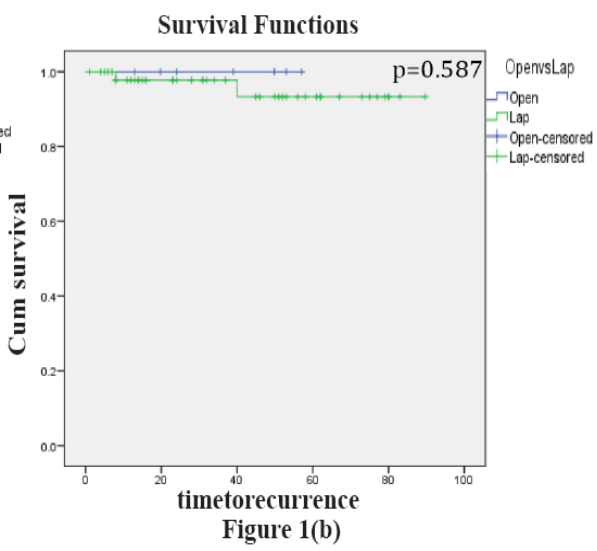

Fig1. Kaplan Meier curve for Survival (1a) and Time to Recurrence (1b) for Stage 1 gastric cancer

Kaplan Meier survival curves were performed for survival and time to recurrence by location of tumour. There was no significant difference in survival and time to recurrence between the 2 surgical techniques for upper and diffuse tumours, however there was significantly better survival and time to recurrence when laparoscopic surgery was performed for mid and

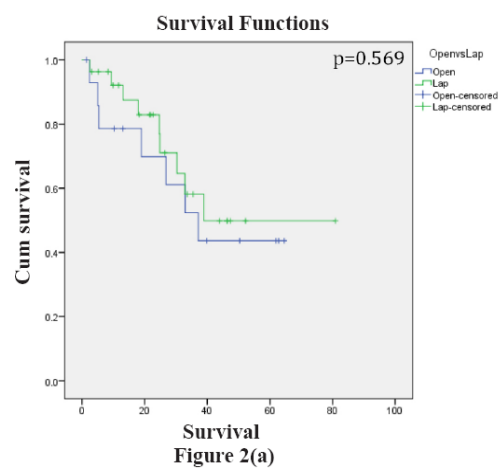

lower tumours (Fig. $4 \& 5$ )

Multivariate analysis performed did not find any significant difference for death rate (odds ratio, $0.71 ; \quad 95 \% \mathrm{CI}: \quad 0.31-1.64), \quad \mathrm{p}=0.427)$ and recurrence (odds ratio, 0.46; 95\%CI: 0.19-1.11, $\mathrm{p}=0.083$ ) in the laparoscopy group compared to open surgery group after adjustment for age, stage and location of the tumour.

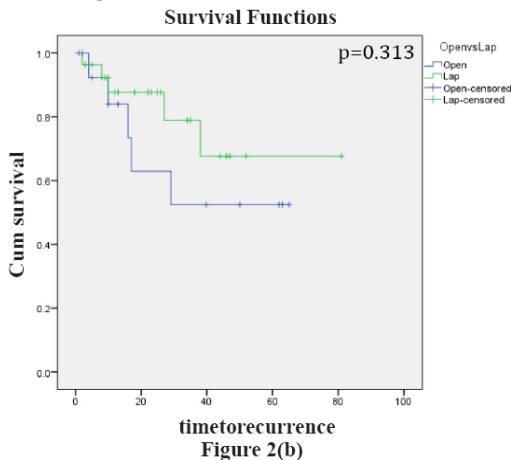

Fig2. Kaplan Meier curve for Survival (2a) and Time to Recurrence (2b) for Stage 2 gastric cancer 
Laparoscopic Versus Open D2 Gastrectomy for the Treatment of Gastric Cancer: a Singapore Institution's Experience over 7 Years
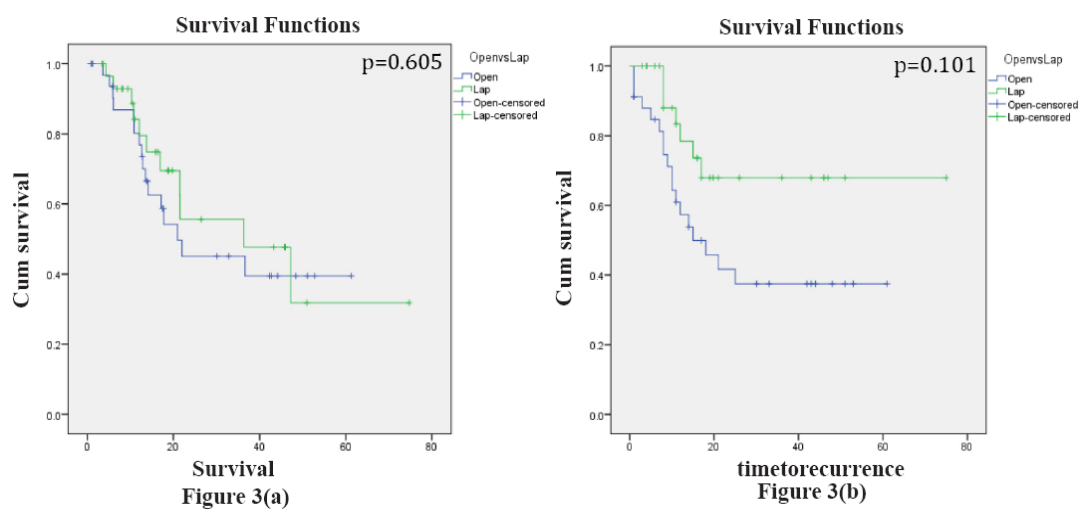

Fig3. Kaplan Meier curve for Survival (3a) and Time to Recurrence (3b) for Stage 3 gastric cancer

Table2. Post-operative Outcomes

\begin{tabular}{|l|l|l|l|l|l|}
\hline & & \multicolumn{1}{|c|}{ All $\mathbf{~ N = 1 6 4 )}$} & \multicolumn{1}{c|}{ Open } & \multicolumn{1}{c|}{ Laparoscopy } & \\
\hline & & \multicolumn{1}{|c|}{$\mathbf{N}(\mathbf{\%})$} & \multicolumn{1}{c|}{$\mathbf{n = 5 8}$} & \multicolumn{1}{c|}{$\mathbf{n = 1 0 6}$} & \multicolumn{1}{|c|}{ P value } \\
\hline No of lymph nodes & mean \pm SD & $34 \pm 18.2$ & $32.2 \pm 18.6$ & $35 \pm 17.9$ & 0.359 \\
\hline Operative time, Mins & mean \pm SD & $253 \pm 78.2$ & $223 \pm 54.8$ & $268 \pm 83.9$ & 0.001 \\
\hline Blood Loss, Millilitres & mean \pm SD & $303.3 \pm 303.8$ & $330 \pm 224$ & $287 \pm 342$ & 0.444 \\
\hline Length of stay, Days & mean \pm SD & $11.1 \pm 10.7$ & $13 \pm 12.2$ & $10.1 \pm 9.7$ & 0.131 \\
\hline Re-operation & No & $157(95.7)$ & $56(96.6)$ & $101(95.3)$ & $>0.999$ \\
\hline & Yes & $7(4.3)$ & $2(3.5)$ & $5(4.7)$ & \\
\hline 30-day morbidity & No & $134(82.2)$ & $43(75.4)$ & $91(85.9)$ & 0.097 \\
\hline & Yes & $29(17.8)$ & $14(24.6)$ & $15(14.2)$ & \\
\hline 30-day mortality & No & $163(99.4)$ & $58(100)$ & $105(99.1)$ & $>0.999$ \\
\hline & Yes & $1(0.6)$ & 0 & $1(0.9)$ & \\
\hline Recurrence & No & $122(74.8)$ & $32(56.1)$ & $90(84.9)$ & $<0.001$ \\
\hline & Yes & $41(25.2)$ & $25(43.9)$ & $16(15.1)$ & \\
\hline Time to recurrence, Months & mean \pm SD & $12.6 \pm 8.8$ & $12 \pm 8.6$ & $13.5 \pm 9.3$ & 0.604 \\
\hline Mortality & No & $108(66.3)$ & $30(52.6)$ & $78(73.6)$ & 0.007 \\
\hline & Yes & $55(33.7)$ & $27(47.4)$ & $28(26.4)$ & \\
\hline Survival, Months & mean \pm SD & $28.8 \pm 21.8$ & $25.6 \pm 19.2$ & $30.5 \pm 23.1$ & 0.173 \\
\hline
\end{tabular}

Table3. 30-day morbidity: Complications

\begin{tabular}{|l|c|c|c|}
\hline & Open & Laparoscopy & \\
\hline & $\mathbf{n = 5 8}$ & $\mathbf{n = 1 0 6}$ & P value \\
\hline Pneumonia & 3 & 3 & \\
\hline $\begin{array}{l}\text { Deep vein thrombosis / } \\
\text { pulmonary embolism }\end{array}$ & 0 & 2 & \\
\hline Anastomotic leak & 3 & 5 & \\
\hline Intra-abdominal collection & 5 & 3 & \\
\hline Duodenal stump leak & 0 & 1 & \\
\hline Ileus & 3 & 1 & 0.097 \\
\hline Total & 14 & 15 & \\
\hline
\end{tabular}
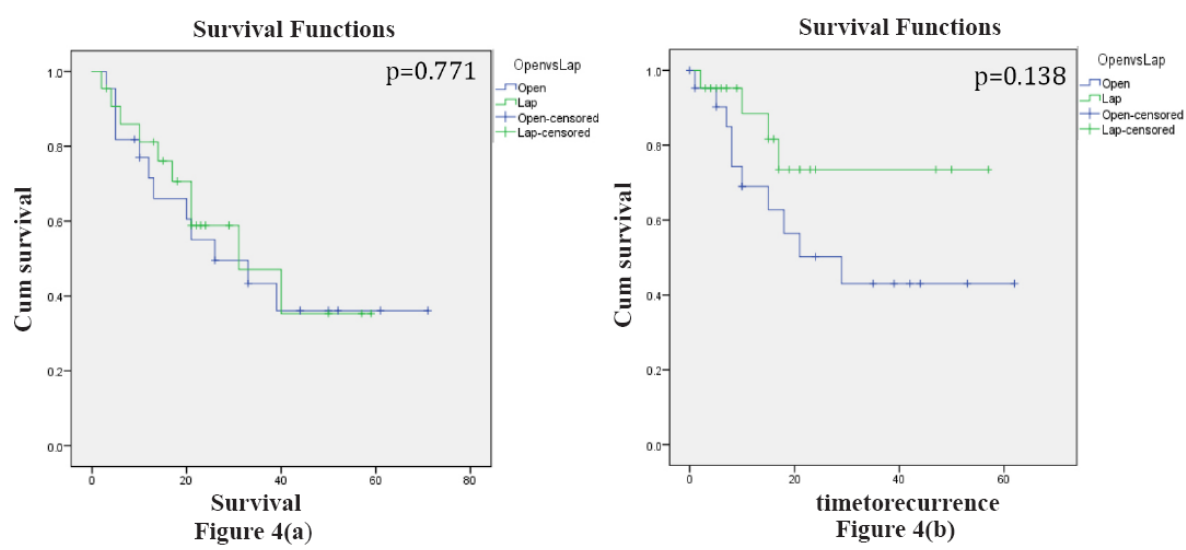

Fig4. Kaplan Meier curve for Survival (4a) and Time to Recurrence (4b) for Upper and Diffuse gastric cancer 

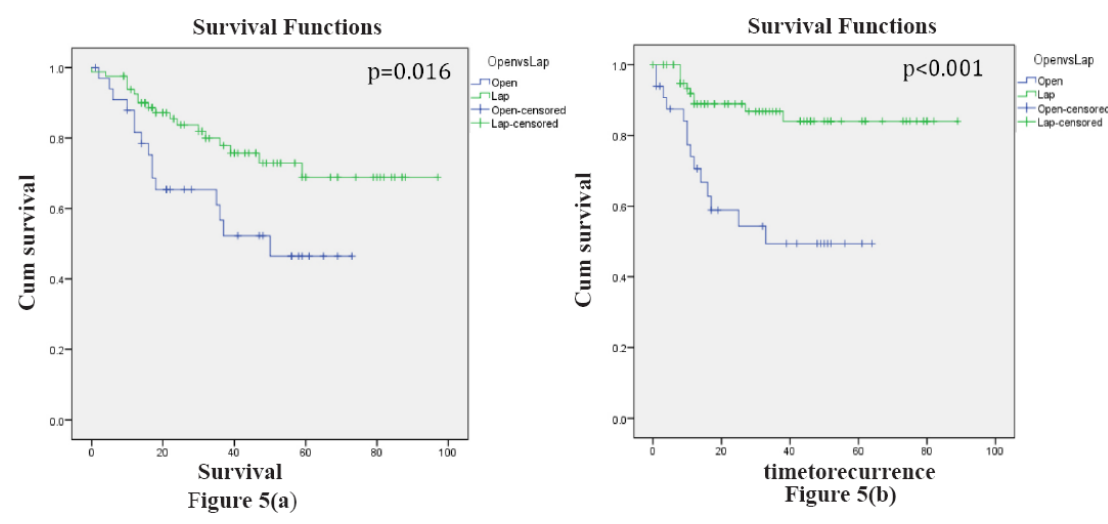

Fig5. Kaplan Meier curve for Survival (5a) and Time to Recurrence (5b) for Mid and Lower gastric cancer

\section{DISCUSSION}

Laparoscopic gastrectomy with D2 lymphadenectomy is widely accepted for early gastric cancer, but its in role advanced gastric cancer remains debatable in view of the technical challenges faced in laparoscopic surgery. In our series, there was no significant difference in the 30-day morbidity $(14.2 \%$ \& $24.6 \%)$ and mortality $(0.9 \%$ \& $0 \%)$ between laparoscopic and open gastrectomy. While laparoscopic surgery took significantly longer than open surgery, there was a trend towards less blood loss and a shorter hospital stay. Li et al (6) showed more rapid postoperative recovery in the laparoscopic gastrectomy group compared to the open gastrectomy group, with significantly earlier first flatus time, diet start time, and significantly shorter hospital stay. The 30-day morbidity and mortality rates in this study are consistent with the rates reported in other centres. The Korean Laparo-endoscopic Gastrointestinal Surgery Study (KLASS) (7) trial report early morbidity of $15.1 \%$ for open gastrectomy and $11.6 \%$ for laparoscopic gastrectomy, while Huscher et al (8) reported morbidity rates of $26.7 \%$ and $3.3 \%$ mortality for laparoscopic gastrectomy. Morbidity and mortality rates are an important indication of the safety and feasibility of an operation.

In our series, there was no difference in the number of lymph nodes harvested whether the operation is performed open or laparoscopic, which is consistent with other centres performing laparoscopic gastrectomy.(6, 9-11) The number of harvested lymph nodes is an objective index of lymphadenectomy. The mean number of lymph nodes harvested $(32.2 \& 35$ in the open and laparoscopic group respectively) was sufficient for stage classification according to the National Comprehensive Cancer Network (NCCN) guidelines (ver 1, 2011), which recommend no less than 15 lymph nodes for radical gastrectomy.

Less patients who underwent laparoscopic gastrectomy received adjuvant chemotherapy, and the disease-free as well as overall survival is significantly longer in the laparoscopic gastrectomy group. This is most likely related to the greater proportion of advanced gastric cancer in the open gastrectomy group. The 5year survival rates of $52.6 \%$ for open gastrectomy and $73.6 \%$ for laparoscopic gastrectomy in our series are comparable with other studies. Hao et al(9) reported 5-year survival rates of $57.65 \%$ and $53.69 \%$ for laparoscopic and open gastrectomy respectively, while Shinohara et al(12) reported survival rates of $68.1 \%$ and $63.7 \%$ for laparoscopic and open gastrectomy respectively. Multivariate analysis did not find any significant difference for death rate and recurrence after adjustment for stage of tumour. Comparisons of same-stage patient survival curves in laparoscopic and open gastrectomy revealed no differences in the 5year survival rates, a finding that is consistent with larger studies. $(9,12)$ This demonstrates that the survival rates of patients with gastric cancer are affected by the stage of the tumour, rather than the surgical method. Pak et al(13) analysed 714 patients who underwent laparoscopic gastrectomy for gastric cancer, and found that the 5-year overall survival rates were $96.4 \%$ for stage I, $83.1 \%$ for stage II, and $50.2 \%$ for stage III gastric cancers. This indicates that laparoscopic gastrectomy for gastric cancer had acceptable oncological outcomes. A metaanalysis by Chen et al(14) showed that the longterm survival and recurrence rates of laparoscopic gastric cancer surgery are comparable to those of open surgery for both early and advanced gastric cancer. 
Neoadjuvant chemotherapy is not widely carried out in our institution; only $5.5 \%$ of the patients in our series underwent neoadjuvant chemotherapy. The last edition of the Japanese Gastric Cancer Association guidelines (4) still consider neoadjuvant chemotherapy investigational while awaiting the results of dedicated ongoing trials.

In our analysis, there was significantly better survival and time to recurrence when laparoscopic surgery was performed for mid and distal tumours, but not for upper and diffuse tumours. Location of tumour may affect the prognosis and type of surgery performed. Tumours in the proximal third of the stomach are likely to be of larger size, have more extensive wall penetration, nodal metastasis and more advanced stage, with an overall worse survival relative to tumours in the antrum(15). Total gastrectomy is performed for proximal tumours and linitisplastica, while subtotal gastrectomy may be performed for distal gastric tumours.

The learning curve of laparoscopic gastrectomy is a steep one. Kim et al showed that a minimum of 50 cases of laparoscopic gastrectomies for early gastric cancer is required to achieve competence and significantly improved operative time.(16) The greater proportion of patients with advanced gastric cancer in the open surgery group in our series is due to careful patient selection for laparoscopic surgery.

Our study has some limitations. It is a retrospective non-randomized study conducted in a single-centre. There are also significant differences between the 2 patient groups with regards to location and stage of the tumour, which affects overall survival and disease-free recurrence. More patients in the open group had previous laparotomies, and this could also have resulted in bias. In our study, the open group had significantly lower operative time with a trend towards higher blood loss. We believe that the higher intra-operative blood loss in the open group could have been contributed by a greater proportion of higher stage tumours and a higher rate of previous laparotomies. $\mathrm{We}$ have attempted to address this through multi-variate analysis and Kaplan Meier analysis stratified by stage of disease and location of tumour. While this study has shown that laparoscopic gastrectomy is comparable to open gastrectomy with regards to technical safety and oncological outcomes, a clear clinical advantage for laparoscopic over open is not demonstrated. Further studies evaluating quality of life and post-operative pain between laparoscopic and open surgery should be conducted.

\section{CONCLUSION}

In our study, there was no difference in shortterm outcomes between laparoscopic and open surgery. Survival and time to recurrence is affected by tumour, rather than the surgical method (14). Laparoscopic gastrectomy with D2 lymph node dissection can be considered a safe and feasible procedure for gastric cancer. Further trials can be carried out to assess potential benefits of laparoscopic gastrectomy over open gastrectomy.

\section{REFERENCES}

[1] Jemal A, Bray F, Center MM, Ferlay J, Ward E, Forman D. Global cancer statistics. CA Cancer J Clin. 2011; 61:69-90.

[2] Saka M, Morita S, Fukagawa T, Katai H. Present and future status of gastric cancer surgery. Jpn J Clin Oncol. 2011; 41:307-13.

[3] Kitano S, Iso Y, Moriyama M, Sugimachi K. Laparoscopy-assisted Billroth I gastrectomy. Surg Laparosc Endosc. 1994; 4:146-8.

[4] Japanese Gastric Cancer A. Japanese gastric cancer treatment guidelines 2010 (ver. 3). Gastric Cancer. 2011; 14:113-23.

[5] Chen XZ, Hu JK, Yang K, Wang L, Lu QC. Short-term evaluation of laparoscopy-assisted distal gastrectomy for predictive early gastric cancer: a meta-analysis of randomized controlled trials. Surg Laparosc Endosc Percutan Tech. 2009; 19:277-84.

[6] Li Q, Wang J, Zhang G, Wang J, Yang B, Zhang Z. Feasibility and safety comparison of laparoscopy-assisted versus open gastrectomy for advanced gastric carcinoma with D2 lymphadenectomy. Jpn J Clin Oncol. 2016; 46:323-8.

[7] Kim HH, Hyung WJ, Cho GS, Kim MC, Han SU, Kim W, et al. Morbidity and mortality of laparoscopic gastrectomy versus open gastrectomy for gastric cancer: an interim report--a phase III multicenter, prospective, randomized Trial (KLASS Trial). Ann Surg. 2010; 251:417-20.

[8] Huscher CG, Mingoli A, Sgarzini G, Sansonetti A, Di Paola M, Recher A, et al. Laparoscopic versus open subtotal gastrectomy for distal gastric cancer: five-year results of a randomized prospective trial. Ann Surg. 2005; 241:232-7.

[9] Hao Y, Yu P, Qian F, Zhao Y, Shi Y, Tang B, et al. Comparison of laparoscopy-assisted and open radical gastrectomy for advanced gastric 
cancer: A retrospective study in a single minimally invasive surgery center. Medicine (Baltimore). 2016; 95:e3936.

[10] Chen QY, Huang CM, Lin JX, Zheng CH, Li P, Xie JW, et al. Laparoscopy-assisted versus open D2 radical gastrectomy for advanced gastric cancer without serosal invasion: a case control study. World J Surg Oncol. 2012; 10:248.

[11] Inaki N, Etoh $\mathrm{T}$, Ohyama $\mathrm{T}$, Uchiyama K, Katada N, Koeda K, et al. A Multi-institutional, Prospective, Phase II Feasibility Study of Laparoscopy-Assisted Distal Gastrectomy with D2 Lymph Node Dissection for Locally Advanced Gastric Cancer (JLSSG0901). World J Surg. 2015; 39:2734-41.

[12] Shinohara T, Satoh S, Kanaya S, Ishida Y, Taniguchi K, Isogaki J, et al. Laparoscopic versus open D2 gastrectomy for advanced gastric cancer: a retrospective cohort study. Surg Endosc. 2013; 27:286-94.
[13] Pak KH, Hyung WJ, Son T, Obama K, Woo Y, Kim HI, et al. Long-term oncologic outcomes of 714 consecutive laparoscopic gastrectomies for gastric cancer: results from the 7-year experience of a single institute. Surg Endosc. 2012; 26:130-6.

[14] Chen XZ, Wen L, Rui YY, Liu CX, Zhao QC, Zhou ZG, et al. Long-term survival outcomes of laparoscopic versus open gastrectomy for gastric cancer: a systematic review and metaanalysis. Medicine (Baltimore). 2015; 94:e454.

[15] Pinto-De-Sousa J, David L, Seixas M, Pimenta A. Clinicopathologic profiles and prognosis of gastric carcinomas from the cardia, fundus/body and antrum. Dig Surg. 2001; 18:102-10.

[16] Kim MC, Jung GJ, Kim HH. Learning curve of laparoscopy-assisted distal gastrectomy with systemic lymphadenectomy for early gastric cancer. World J Gastroenterol. 2005; 11:750811.

Citation: Danson Yeo, Enming Yong, Charleen Yeo, Jaideepraj Rao, Aaryan Koura, Sanghvi Kaushal, Aung MyintOo. Laparoscopic Versus Open D2 Gastrectomy for the Treatment of Gastric Cancer: a Singapore Institution's Experience over 7 Years.2019; 5(1):8-15. DOI: http://dx.doi.org/10.2 0431/2455-572X.0502003

Copyright: (C) 2019 Authors. This is an open-access article distributed under the terms of the Creative Commons Attribution License, which permits unrestricted use, distribution, and reproduction in any medium, provided the original author and source are credited. 